\title{
Cystic Hydatid Disease in Southern Sudan
}

D.K. Lado, MBBS, FS SMSB, Juba Teaching Hospital, Juba, South Sudan

Correspondence and reprint requests to:

Dr. D.K. Lado, Juba Teaching Hospital, P.O. Box 88, Juba, South Sudan, Email: kuronlado@yahoo.com

\section{Abstract}

OBJECTIVE: To document the experience with cystic hydatid disease at a teaching hospital in South Sudan.

DESIGN: A prospective analysis of clinical data collected from patients admitted and treated for cystic hydatid disease between August 2004 and August 2007.

SETTING: Juba Teaching Hospital.

PATIENTS: One hundred and seventeen patients treated for cystic hydatid disease were evaluated.

RESULTS: There were 89 males (76\%) and 28 (24\%) females in the study group. The age range was 20-60 years with a mean of 40 years. Most of the patients $(98 \%)$ came from the Eastern bank of River Nile. The diagnosis was mainly clinical and the most common presentation was a painless abdominal mass. The mean duration of symptoms was two years. Cysts were located in the liver, lungs and other organs in $70 \%, 8 \%$ and $22 \%$ of cases respectively. Operative management was conservative in $93 \%$ of patients. There were no peri-operative complications. Two patients had recurrent disease during follow-up.

CONCLUSION: Cystic hydatid disease is common in South Sudan. The cyst localization is diverse. Conservative surgery was effective with both low morbidity and recurrence of the disease. Prevention of the disease through public education and incorporation of hydatid control in school curricula may reduce the burden.

\section{Introduction}

Hydatid disease is common in sheep and cattlerearing regions and is considered endemic in several parts of Africa (1). The highest recorded incidence of the disease is among the Turkana in Northern Kenya affecting more than 5\% of the population (2). Sudan borders Kenya, and like in Northern Kenya, cattle rearing is common. High incidences of hydatid disease have been recorded among the Taposa (3.2\%) of Southern Sudan $(2,3)$. Within its ten states, the endemic areas are in the Jonglei and Eastern Equatoria states (Figure 1) affecting the tribes that inhabit these areas, including the Taposa, Buya and Turkana $(3,4)$. Information regarding local disease presentation in these areas is scarce. Collection of local data to identify high risk situations is important in developing treatment and preventive strategies like the guinea worm and the Onchocerca volvulus (OV) programs in Sudan. This study describes the clinical presentation, anatomical locations and management of hydatid disease at the Juba Hospital.

\section{Patients and methods}

This was a prospective descriptive study of 117 patients diagnosed with cystic hydatid disease at the Juba Teaching Hospital between August 2004 and August 2007.

Juba Hospital is a 512 bed facility that receives patients from all ten states of Southern Sudan (Figure 1) and is the main teaching hospital for Juba University. In addition to demographic 


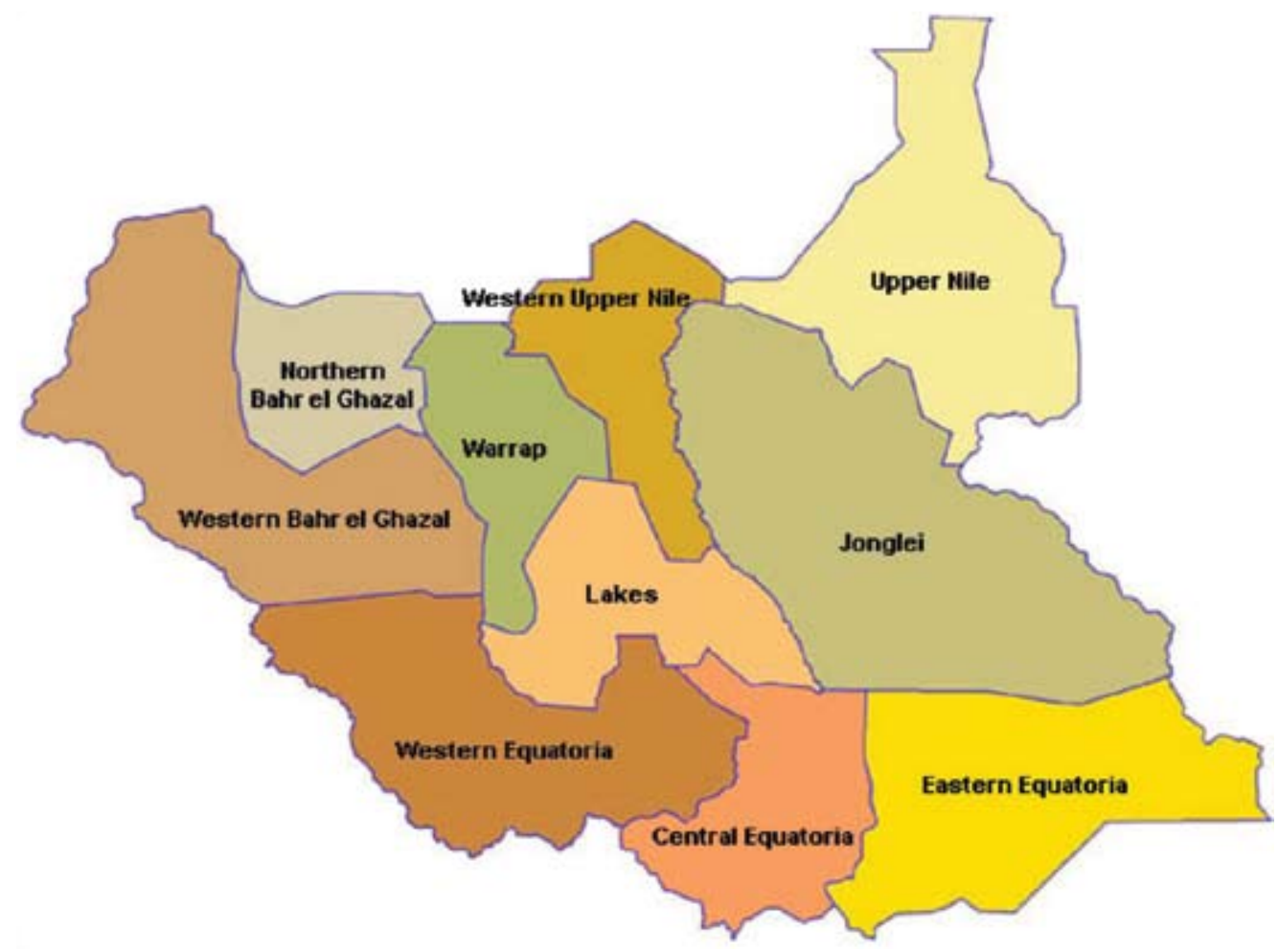

data and region of origin, information about duration of symptoms, findings on physical examination, treatment regimens and complications were documented.

\section{Results}

There were 89 males (76\%) and 28 (24\%) females in the study group. The age range was 20-60 years with a mean of 40 years. Most of the patients were younger than 40 years with the peak age in the forth decade (Figure 2). Most of the patients in this study (98\%) came from the Eastern bank of River Nile from Jonglei and Eastern Equatoria states inhabited by the Murle, Taposa, Didinga, Buya and Lokoro Tribes. The proportion of patients from Pibor in Jonglei state, Kapoeta in Eastern Equatoria state and Lafon area in Jonglei state were 65\%, 18\% and $15 \%$ respectively.

The most common presentation was an abdominal mass (Table 1). Unusual anatomical sites of hydatid cysts included the breast and neck region (Table 1). Six patients presented with painless breast lumps (Figure 3) that were mobile and felt like large fibroadenomas. Six nodular neck swellings were found to be hydatid cysts and three abdominal wall swellings were subcutaneous hydatid cysts.

The diagnosis was mainly clinical. Ultrasonography and CT scans were rarely used. The cysts were located in the liver, lungs and other organs in $70 \%, 8 \%$ and $22 \%$ of cases respectively (Figure 4).

Sixty one percent of the patients in this review admitted that they had had symptoms for at least one year before seeking medical advice. The mean duration of symptoms was two years. For the patients whose swellings had associated pain and systemic symptoms (n $=19,16 \%$ ), the presentation was earlier, with a mean duration being eight months.

All the patients in this study received medical treatment with Albendazole (400mg 12 hourly) for at least four weeks. Most patients $(93 \%)$ were treated surgically. Surgery was conservative (non-resectional), eradicating the macroscopic parasite after injecting the cyst with a scolicidal agent. The remaining 7\% received medical treatment alone because of disseminated disease. 
The majority of patients $(92 \%)$ had a solitary cyst while $8 \%$ had cystic lesions in other organs in addition to hepatic cysts. Radical resectional procedures, wedge resection and lobectomies were not performed in any patients.
There were no intra-operative complications documented (anaphylactic shock or cyst rupture with spillage). Two patients had recurrent disease during the follow up period and were treated medically with Albendazole.

Table 1: Presentation of cystic hydatid disease in South Sudan

\begin{tabular}{lcc}
\hline Characteristic & Number $(\mathrm{n}=117)$ & $(\%)$ \\
\hline Gender & 89 & 76 \\
Male & 28 & 24 \\
Female & & 76 \\
Symptom/Signs & 89 & 5 \\
Abdominal mass & 6 & 2 \\
Nausea/ vomiting & 2 & 9 \\
Weight loss & 11 & 5 \\
Other masses & 6 & 3 \\
Breast mass & 3 & 100 \\
Neck swelling & 117 & 2 \\
\hline Total & & 65 \\
\hline Region of origin & 76 & 18 \\
Pibor (JS) & 21 & 15 \\
Kapoeta (EES) & 18 & 2 \\
Lafon (JS) & 2 & \\
Other & & \\
\hline
\end{tabular}

JS = Jonglei State; EES = Eastern Equatoria State

Figure 2: Age distribution of hydatid cyst patients, Juba Hospital

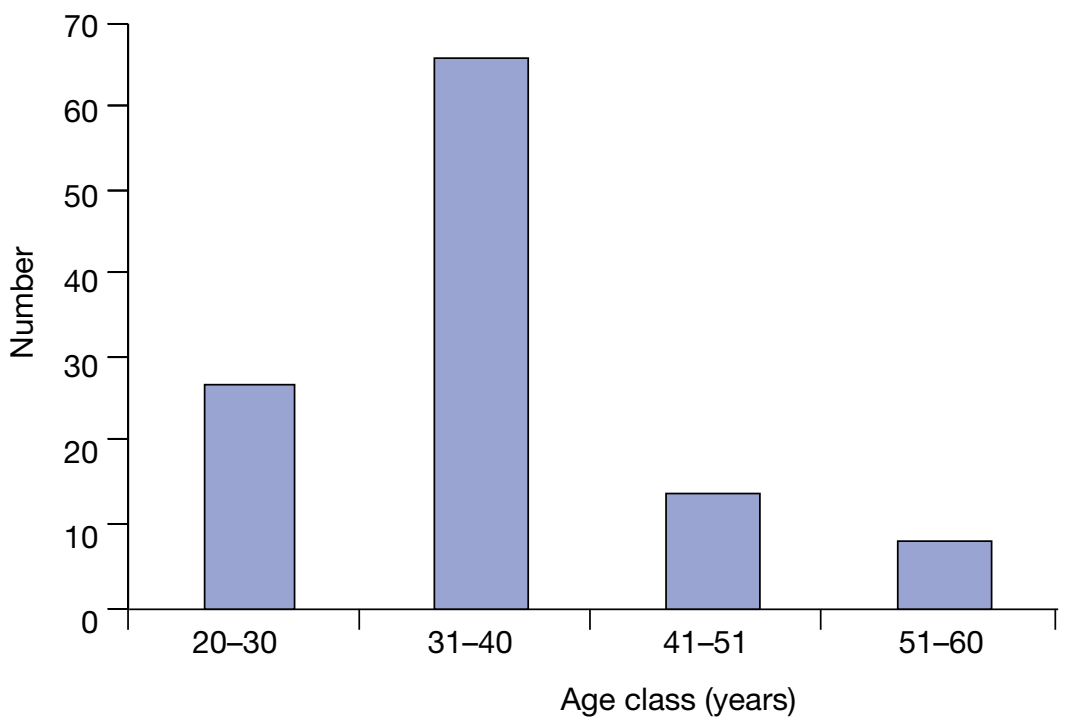


Figure 3: Hydatid cysts in the breast

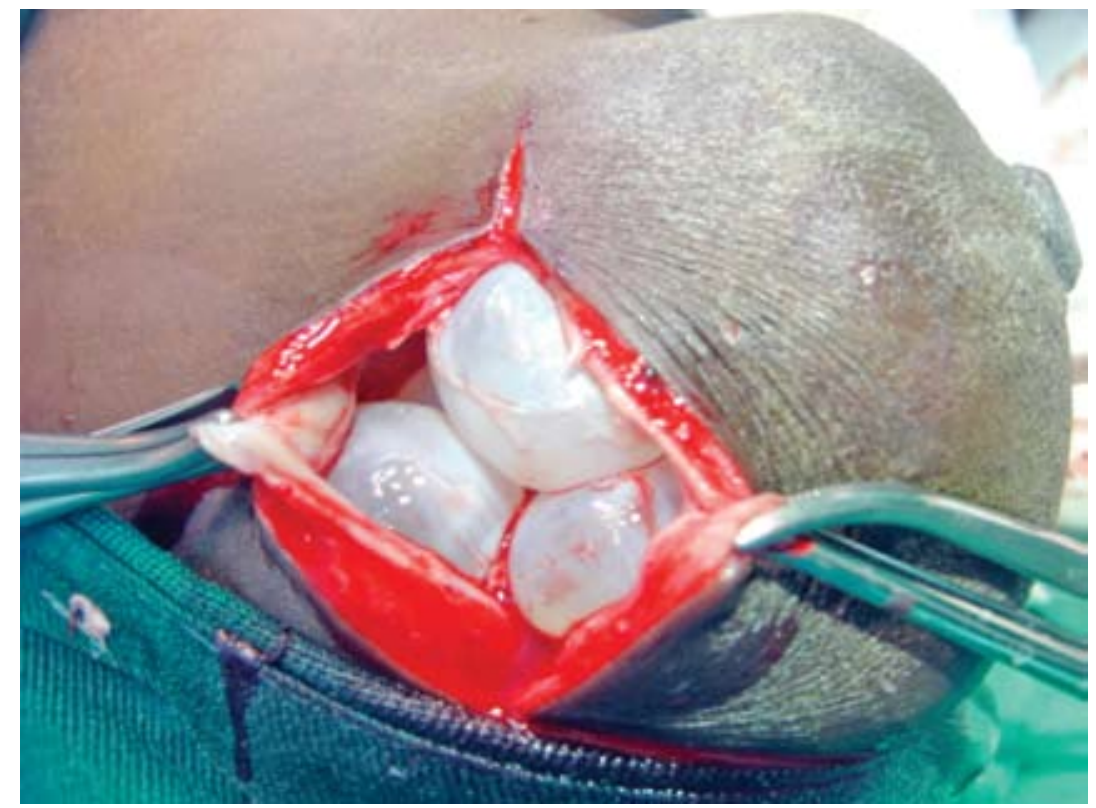

Figure 4: Abdominal radiograph outlining hydatid cyst wall located in the abdomen. This displaced the right ureter to the left

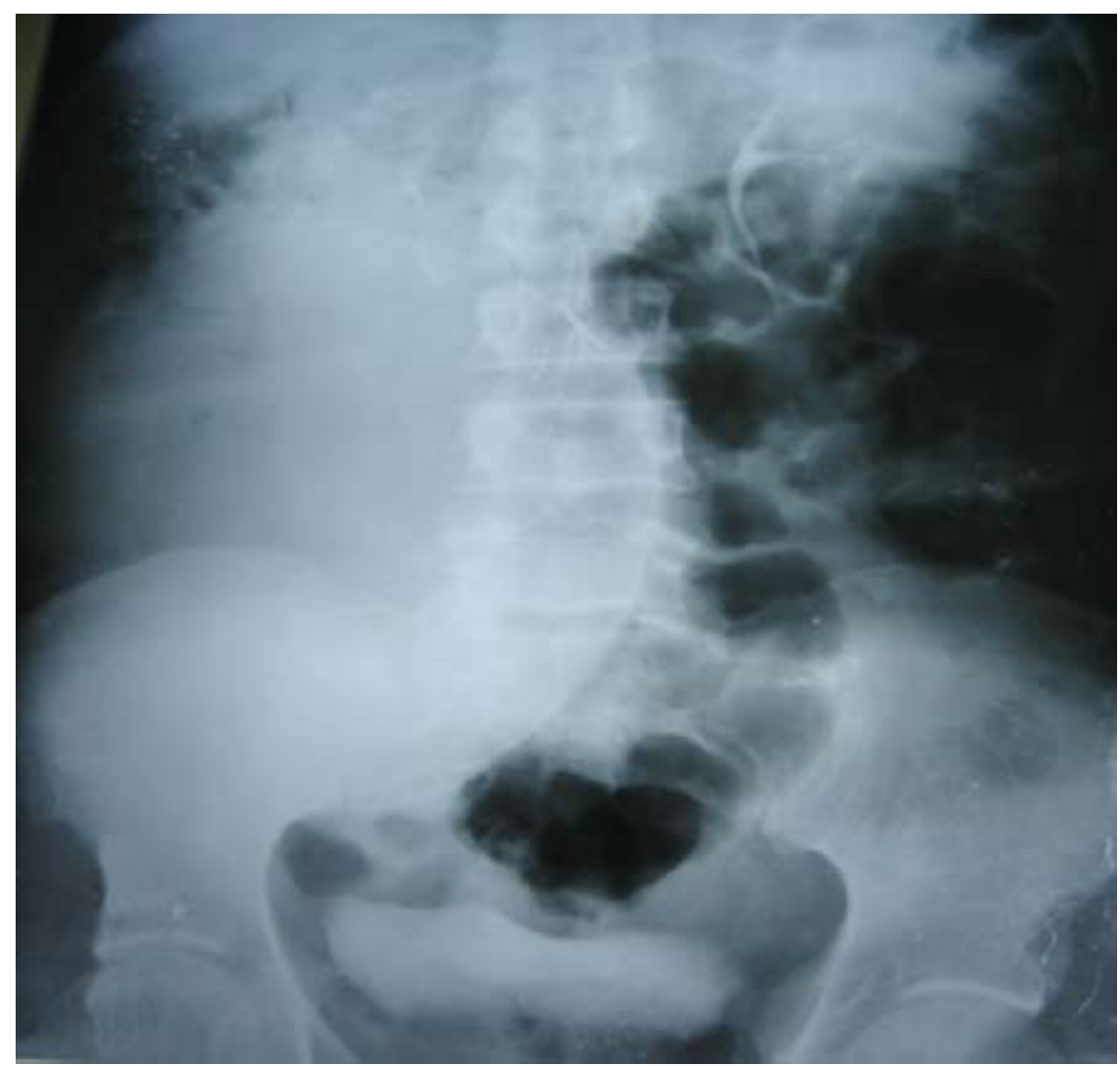




\section{Discussion}

The results of this study have shown a higher male prevalence. This is consistent with other data from the Sudan $(2,3)$ but at variance with the gender profile among the Turkana of Kenya (2) and in the Hamar region in Ethiopia (5). In Kenya's Turkana community, females outnumber males (ratio of 2:1) (2). In Hamar, the data available also shows a higher risk for women where the overall community prevalence was $0.7 \%$, but the rate in women significantly higher at $4.7 \%$ (5).

Hydatid disease (Echinococcosis) is endemic in areas where there is close contact between humans and domesticated animals. The life cycle of Echinococcus involves a definitive and an intermediate host. Humans are accidental hosts. Two species of Echinococcus (E. granulosus and E. miltilocularis) are the most common and involve different hosts in different geographical zones. There are however, strain variations within species (E. granulosus may be split into several distinct sub-species) (6) and these may have different infectivities (7). The adult tapeworm of E. granulosus is usually found in a dog or another canid, while foxes, canids, or occasionally cats harbor the E. multilocularis tapeworm. The adult tapeworm inhabits the small intestine of the definitive host. Their eggs are expelled in the faeces of the definitive host and released to the environment. Susceptible intermediate hosts or humans can then be infected. Within the intermediate or accidental host, the eggs hatch into oncospheres which penetrate the intestinal mucosa and enter the blood and/or lymphatic system and migrate to the visceral organs, particularly to the liver. In the visceral organs, the oncospheres form fluidfilled cysts which may develop into multiple layers to become the hydatid cysts.

The young age at diagnosis in the present study is also consistent with African literature. In the study at Tikur Anbessa hospital, the mean age was 35 years (8). Young people tend to work outdoors and are responsible for most animal rearing in South Sudan communities and in the other regional communities.

The diagnosis was made clinically in the majority of cases. As reported in other studies, most patients complain of abdominal swelling $(65 \%)$ with the disease affecting the liver in 52$77 \%$ of cases (9). More than $60 \%$ of the patients in this study only sought treatment after at least one year from the time they noted symptoms. They presented earlier when the swellings were associated with other symptoms of pain, nausea, vomiting, or weight loss. This was probably due to the fact that hydatid cysts grow slowly and only cause symptoms when big enough to cause pressure or obstruction to the nearby structures, or cause a cosmetic abnormality due to their size.

Localization of hydatid cysts outside the abdomen and chest cavity is rare (10). In the current series, six patients $(5 \%)$ presented with breast masses that were thought to be fibroadenomas. In literature, there is little mention of hydatid cyst as a differential diagnosis of a giant fibroadenoma in the breast. Other unusual sites found in this cohort included seeding of cysts in the neck and the anterior abdominal wall. In a case report by Dilege et al (11), a $4 \mathrm{~cm}$ axillary cyst, $12 \mathrm{~cm}$ liver cyst and a $10 \mathrm{~cm}$ lung cyst all co-existed in a 16 year old in a hydatid endemic area.

Most of the patients came from three main areas on the Eastern bank of the Nile River. The majority were from Pibor in Jonglei state, inhabited mainly by Murle, a nomadic tribe in the region. The Taposa in Kapoeta (Eastern Equatoria State) are also a nomadic tribe at the Sudanese-Kenyan border. Earlier ultrasound prevalence studies have shown a high prevalence of $3.2-3.5 \%$ for cystic hydatid cystic disease among the Taposa $(2,3)$.

Imaging and serological investigations for the diagnosis of hydatid disease were not available in our hospital. Conventional open surgery, after a period of four weeks on Albendazole $400 \mathrm{mg}$ twice a day, was the mode of treatment for all the patients where surgery was indicated. Percutaneous Aspiration Injection and Reaspiration techniques were not used although there is ample data to show equivalence to surgery in terms of efficacy and recurrence rates for Gharbi I-III cysts (12-14). There was no intra-operative anaphylactic shock or rupture in this series, possibly due to the preoperative medical treatment. Recurrence rate 
of $2 \%$ after two years of follow up in patients operated for hydatid disease is equivalent to international recurrence rates. The possibility of acquiring a totally new infection in an endemic area is also a possibility. Therefore, medical treatment following surgery may need to be prolonged to 6-8 weeks.

In conclusion, hydatid cystic disease is a common entity in South Sudan. The cyst localization is diverse. Conventional surgery for the disease is effective with low morbidity and recurrence. A program to prevent and control the disease, similar that of guinea worm and OV needs to be started. This will entail education on personal hygiene, satisfactory disposal of carcasses , meat inspection by public health workers and regular deworming of definitive hosts.

\section{Acknowledgement}

Dr. Louis Edward Danga for his support and encouragement and Dr. Baak Mangong, for taking care of the patients.

\section{References}

1. Elton C., Lewis M. and Jordan M.H. Unusual site of hydatid disease. Lancet. 1999; 355: 2132.

2. Macpherson C.N., Spoerry A., Zeyhl E., et al. Pastoralists and hydatid disease: an ultrasound scanning prevalence survey in East Africa. Trans. $R$. Soc. Trop. Med. Hyg. 1989; 83(2): 243-247.

3. Magambo J.K., Zeyhle E. and Wachira T. Hydatid disease in Taposaland, Southern Sudan. Afr. J. Health Sci. 1998; 5: 129-132.
4. Magambo J.K., Hall C., Zeyhle E. et al. Prevalence of human hydatid disease in Southern Sudan. Afr. J. Health Sci. 1996; 34: 154-156.

5. Kungsoyr P., Courtright P. and Hendriksoon T.H. Hydatid disease in the Hamar of Ethiopa: A public problem for women. Tran. Royal Soc. Trop. Med. $\mathcal{E}$ Hyg. 1993; 87(3): 340-348.

6. Romig T., Dinkel A. and Mackenstedt U. The present situation of echinococcocosis in Europe. Parasitol. Int. 2006; 55 Suppl: S187.

7. Eckert J. and Thompson R.C. Intraspecific variation of Echinoccocus granulosus and related species with emphasis in their infectivity to human. Acta Trop. 1997; 64: 19.

8. Biluts H., Minas M. and Bekele A. Hydatid disease of the liver: A12 year experience of surgical management. East Central Afr. J. Surg. 2006; 2: 54-60.

9. Sayek I. and Onat D. Diagnosis and treatment of uncomplicated hydatid cyst of the liver. World J. Surg. 2001; 25: 21-27.

10. Leow C.K. and Lau W.Y. Soft tissue images. Hydatid disease of the liver. Can. J. Surg. 2000; 43: 330-331.

11. Dilege S., Aksoy M., Okan I., et al. Hydatid cystic disease of the soft tissues with pulmonary and hepatic involvement: Report of a case. Surg. Today. 2003; 33: 69-71.

12. Khuroo M.S., Wani N.A., Javid G., et al. Percutenous drainage compared with surgery for hepatic hydtid cysts. N Engl. J. Med. 1997; 337: 881-887.

13. Smego R.A., Bhatti S., Khaliq A.A., et al. Percutenous aspiration - injection - reaspiration drainage plus albendazole or mebendazole for hepatic echinococcosis: a meta-analysis. Clin. Infec. Dis. 2003; 37: 1073-1083.

14. Nasseri Moghaddam S., Abrishami A. and Malekzadeh R. Percutenos needle aspiration, injection and reaspiration with or without benzimidazole coverage for uncomplicated hepatic hydatid cysts (Review). Cochrane Database Sys. Rev. 2006; 19(2): CD 003623. 